九州大学学術情報リポジトリ

Kyushu University Institutional Repository

\title{
Association of HSPB1 and CRYAB SNPs with Chicken Meat Quality and Robustness in Five Lines of Korean Native Chicken
}

Seo, Dongwon

Division of Animal and Dairy Science, College of Agriculture and Life Sciences, Chungnam National University

Park, Hee-Bok

Division of Animal and Dairy Science, College of Agriculture and Life Sciences, Chungnam National University

Jung, Samooel

Division of Animal and Dairy Science, College of Agriculture and Life Sciences, Chungnam National University

Manjula, Prabuddha

Division of Animal and Dairy Science, College of Agriculture and Life Sciences, Chungnam National University

他

https://doi.org/10.5109/1564093

出版情報: 九州大学大学院農学研究院紀要. 61 (1)，pp.127-132，2016-02-29. Faculty of Agriculture, Kyushu University

バージョン :

権利関係 : 


\title{
Association of HSPB1 and CRYAB SNPs with Chicken Meat Quality and Robustness in Five Lines of Korean Native Chicken
}

\author{
Dongwon SEO ${ }^{1}$, Hee-Bok PARK ${ }^{1}$, Samooel JUNG ${ }^{1}$, Prabuddha MANJULA ${ }^{1}$, \\ Nuri CHOI ${ }^{1}$, Shil JIN ${ }^{1}$, Kang-Nyeong HEO ${ }^{2}$, Cheorun JO $^{3}$, \\ Takafumi GOTOH and Jun Heon LEE ${ }^{1 *}$
}

\author{
Kuju Agricultural Research Center, Kyushu University, Kuju 4045-4, \\ Taketa City, 878-0201, Oita, Japan \\ (Received November 10, 2015 and accepted November 19, 2015)
}

\begin{abstract}
The clinical-chemical traits of blood serum are important biomarkers that can be used to investigate health and metabolic status, both of which can affect meat quality traits. In this study, the SNPs in the genes HSPB1 (g. 526A > G; 5'UTR) and CRYAB (g. 2471T > C; exon 2) were investigated via an association analysis with meat quality and clinical-chemical traits. In total, 597 native Korean chickens were included in the study. There were no significant associations between the SNP in CRYAB and either meat quality or serum traits. On the other hand, the SNP in HSPB1 was significantly associated $(\mathrm{P}<0.05)$ with water-holding capacity (WHC), lightness $\left(\mathrm{L}^{*}\right)$, and yellowness $\left(\mathrm{b}^{*}\right)$ of the thigh muscle. In addition, two clinical-chemical traits, high-density lipoprotein (HDL-c) and amylase (Amy), were significantly associated with this SNP. Of these, the WHC, $L^{*}$, and $b^{*}$ values of the thigh muscle have the dominant effects only, while Amy trait exhibits both additive and dominant effects. These results can provide useful information that can facilitate the improvement of chicken meat quality, and the understanding of the relationship between blood metabolism and meat quality.
\end{abstract}

Key words: candidate gene, clinical-chemical trait, Korean native chicken, meat quality

\section{INTRODUCTION}

With the rapid globalization and economic growth in recent years, consumer concerns about food selection have changed dramatically. For example, consumers now consider the nutritional value and sensory attributes of the meat and meat products when making purchasing decisions. The sensory characteristics of meat include meat color, flavor, juiciness, and tenderness, all of which can affect a consumer's decision. Meat tenderness is the most important factor in meat selection, because it primarily affects eating quality and is directly evaluated by consumers (Destefanis et al., 2008; Kim et al., 2009). The tenderness of meat is mainly affected by the contents of the muscle fibers, as well as their structure and protein restriction enzymes (Calkins et al., 1981).

In the case of the Korean native chicken (KNC), the National Institute of Animal Science (NIAS) in Korea has launched a project to conserve five lines of KNC. These lines are mainly divided by feather color (gray, black, red, white, and yellow). KNCs are highly favored by Korean consumers, because of their unique taste and quality. However, a large proportion of the demand for chicken meat is fulfilled by a few fast-growing imported chicken breeds. While approximately $10 \%$ of chicken meat is that

\footnotetext{
Division of Animal and Dairy Science, College of Agriculture and Life Sciences, Chungnam National University, Daejeon 305-764, Korea

Poultry Science Division, National Institute of Animal Science, Rural Development Administration, Cheonan 331-801, Korea

Department of Agricultural Biotechnology and Research Institute of Agriculture and Life Science, Seoul National University, Seoul 151-921, Korea

* Corresponding author (E-mail: junheon@cnu.ac.kr)
}

of KNCs, the Korean government is trying to increase the proportion to $30 \%$ within the next few years. However, the KNC breed requires improvement, because they are less productive and provide meat of a less desirable texture than broiler chickens. Therefore, the development of desirable characteristics and the improvement of KNC meat tenderness will be an important component of enabling KNCs to compete in the market against commercial broilers.

Livestock animals are severely affected by environmental stress when kept in a small space. In the case of KNCs, their health deteriorates, with significant negative consequences for their productivity. In this respect, maintenance or improvement of their health status would improve their adaptability to limited and dynamic environment conditions: an important part of overcoming the challenges of global warming. With respect to this problem, the KNC is highly adaptable and thus is capable of surviving severe environmental changes. Finding the causal genetic variants for the differences among the clinical-chemical traits of different chicken breeds will be a useful tool for improving meat tenderness. This can be accomplished efficiently using gene markers linked to meat tenderness (Lim et al., 2012). Quantitative trait loci (QTL) and candidate gene, proteomics, and genome wide association studies have been performed to elucidate the mechanisms of meat quality and development (Zhang et al., 2008; Guillemin et al., 2011; D'Alessandro et al., 2012; Sun et al., 2013).

The expression of Heat Shock Protein Beta 1 (HSPB1) and Crystalline Alpha B (CRYAB) genes is induced by expression of the heat shock protein (HSP) $27 \mathrm{Kda}$ protein, which is affected by either environmental stress or developmental changes. After slaughter, the 
proteins expressed prior to death are responsible for the inhibiting the apoptosis involved in actin rigor. It has been speculated that muscle cell apoptosis could affect meat characteristics. In this context, the main role of the expressed protein (heat shock protein $27 \mathrm{Kda}$ ) is to facilitate recovery from damage due to the production of stress proteins (Herrera- Mendez et al., 2006; Bernard et $a l ., 2007)$. In fact, many candidate gene studies have found that stress has an effect on the tenderness of meat, especially in bovine meat. In proteomics research, the association of protein production with meat tenderness and meat quality has been established.

The focus of this study was to identify candidate genes or genetic markers that may affect meat quality and animal robustness, and evaluate their potential utility in the improvement of the meat quality.

\section{MATERIALS AND METHODS}

\section{Animals and the measurement of phenotypic traits}

Eighty-eight parents (G0) of five Korean native chicken lines, consisting of 15 sires and 73 dams, were mated to produce 597 offspring (G1). A within-line mating design was used in this study. The birds were reared under the same feeding and control environment system, and slaughtered using the same procedure in same environment, provided by the National Institute of Animal Science, Republic of Korea. Of these offspring, 593 G1 individuals were used to measure the traits in this study. The G1 offspring were divided into 109 gray (G), 90 black (L), 135 red (R), 125 white (W), and 134 yellow (Y) lines based on their plumage colors. This study was conducted according to the recommendations of "The Guide for the Care and Use of Laboratory Animals," published by the Institutional Animal Care and Use Committee of the National Institute of Animal Science (2012-C-037) in Korea. Genomic DNA was extracted from blood samples collected from the wing vein using the manual extraction method (Miller et al., 1988). The extracted genomic DNA concentration was measured using NanoDrop 2000C spectrophotometer (Thermo Scientific, USA), and samples were stored at $-20^{\circ} \mathrm{C}$ until use. The phenotypic traits of meat quality and clinical-chemical traits were measured in a previous study (Jung et al., 2015).

\section{Genotype analysis}

The heterogeneous single nucleotide polymorphisms (SNPs) in HSPB1 and CRYAB were filtered from the KNC SNP annotation database. Direct sequencing of the can- didate genes was performed in order to validate the variations in the genes. A forward and reverse primer pairs were designed to include the target SNP areas of each gene (Table 1).

The PCR mixture contained $10 \mathrm{pmol}$ of primer pair, $50 \mathrm{ng}$ of gDNA, $1 \times$ buffer, $1.5 \mathrm{mM}$ of $\mathrm{MgCl}_{2}$ buffer, $0.2 \mathrm{mM}$ of dNTPs, and 2 units of HS Taq polymerase (GenetBio, Korea). The volume was then adjusted by adding $20 \mu \mathrm{L}$ of distilled water. The size of each amplicon was confirmed via electrophoresis on $2 \%$ agarose gels with a 100-bp standard marker. The genotype of each gene was identified using the restriction fragment length polymorphism (RFLP) method.

The reaction was performed in a $20 \mu \mathrm{L}$ reaction volume composed of 1 unit of restriction enzyme, $15 \mu \mathrm{L}$ of PCR product, $1 \times$ buffer, and $5 \mu \mathrm{L}$ distilled water. The reaction conditions were as follows: a $20 \mathrm{~min}$ incubation at $65^{\circ} \mathrm{C}$ for $H S B P 1$ and a $16 \mathrm{~h}$ incubation at $37^{\circ} \mathrm{C}$ for $C R Y A B$. The sizes of restricted fragments were confirmed via electrophoresis on a 3\% agarose gel with a $100 \mathrm{bp}$ standard marker.

\section{Statistical analysis of phenotype data and associa- tion tests}

The ascertainment of normality and the descriptive statistical analysis of meat quality and clinical-chemical traits were carried out using MINITAB® Release 14 (MINITAB Inc., USA). The parentage tests of the SNPs were confirmed using the CRI-MAP program.

We applied a linear mixed-effects model to the SNP association analyses of the genes and traits, with simultaneous consideration of the familial structure of the $\mathrm{KNC}$ resource population:

$$
\begin{array}{r}
\mathrm{Y}_{\mathrm{ijklm}}=\mu+\mathrm{S}_{\mathrm{i}}+\mathrm{B}_{\mathrm{j}}+\mathrm{L}_{\mathrm{k}}+\mathrm{G}_{1}+\mathrm{b} 1 \mathrm{CW}_{\mathrm{ijklm}}+\mathrm{A}_{\mathrm{ijklm}}+\varepsilon_{\mathrm{ijklm}} \\
\text { (MODEL 1) }
\end{array}
$$

where, $\mathrm{Y}_{\mathrm{ijklmn}}$ represents the measured phenotype; $\mu$ represents the population mean, $\mathrm{S}_{\mathrm{i}}$ is the fixed effect of ith sex, $B_{j}$ is the fixed effect of jth batch (two levels), Lk is the fixed effect of kth line (five levels), $\mathrm{G}_{1}$ is the fixed effect of lth genotype (three levels) of HSPB1 or CRYAB, $\mathrm{b}_{1}$ is a regression coefficient, $\mathrm{CW}_{\mathrm{ijklm}}$ is the covariate for the carcass weight, $\mathrm{A}_{\mathrm{ijkkm}}$ is the random additive polygenic animal effect, and $\varepsilon_{\mathrm{ijklm}}$ is the random residual effect. The mean and variance of the random additive polygenic animal effects can be defined as $\mathrm{A} \sim \mathrm{N}\left(0, \mathbf{A} \sigma_{\mathrm{a}}^{2}\right)$, where $\mathbf{A}$ is based on the relationship matrix computed using the nuclear families in this study, and $\sigma_{\mathrm{a}}^{2}$ is the additive poly-

\begin{tabular}{|c|c|c|c|c|c|}
\hline Gene & Primer sequence & Region & $\begin{array}{c}\text { Annealing } \\
\text { Tm. }\end{array}$ & $\begin{array}{l}\text { Product } \\
\text { size }\end{array}$ & $\begin{array}{c}\text { Restriction } \\
\text { Enzyme }\end{array}$ \\
\hline HSPB1 & $\begin{array}{l}\text { F: ATTGACCTTGGGATGTTGGA } \\
\text { R: TTCTGACCTCTCCCCTCTCC }\end{array}$ & $\begin{array}{l}\text { g.526 } \\
\text { (5’UTR) }\end{array}$ & 57 & 586 & $\operatorname{Taq} \mathrm{I}$ \\
\hline$C R Y A B$ & $\begin{array}{l}\text { F: AATGCTGTGCATGAATGGAA } \\
\text { R: GATGGGCAATCCCTGTTATG }\end{array}$ & $\begin{array}{l}\text { g.2471 } \\
\text { (exon 2) }\end{array}$ & 50 & 840 & BssSI \\
\hline
\end{tabular}

Table 1. Description of the PCR primers and restriction enzymes used to genotype the SNPs in HSPB1 and CRYAB genes 
genic variance. The mean and variance of the residual random effect of individuals can be defined as: $\varepsilon \sim \mathrm{N}(0$, I $\sigma_{\mathrm{a}}^{2}$ ), where $\mathbf{I}$ is the identity matrix and $\sigma_{\mathrm{a}}^{2}$ is the residual variance.

The significance of the fixed effects in MODEL 1 was computed using the Wald procedure implemented in ASReml-R. P-values <0.05 were considered statistically significant. To estimate the genotypic values and standard error of each SNP genotype, the predict command in ASReml-R was used (Gilmour et al., 2009). In order to estimate the additive and dominance coefficients of each SNP in HSPB1 or CRYAB, Gl in the MODEL 1 was replaced with the additive variable $\mathrm{X}_{\text {additive }}$ (coded as $1,-1$ for the two homozygotes, 0 for heterozygote), and the dominance variable $\mathrm{X}_{\text {dominance }}$ (coded as 0 for two homozygotes, 1 for heterozygote). Then, trait values were regressed onto the additive and dominance coefficients at each SNP marker.

\section{RESULTS AND DISCUSSION}

\section{Associations with meat quality traits}

In this study we selected a functional candidate gene, $H S P B 1$, which may affect the meat quality and clinicalchemical traits of chickens. A specific SNP in HSPB1, g.526A $>$ G (5’UTR) has significant dominant associations with the water holding capacity (WHC), lightness ( $\left.\mathrm{L}^{*}\right)$, and yellowness $\left(\mathrm{b}^{*}\right)$ values of the thigh muscle. The ultimate $\mathrm{pH}(\mathrm{pH} 2)$, tended to be significantly associated with HSPB1 g.526A > G $(\mathrm{P}=0.086)$. However, did not detect any significant association with $C R Y A B$ g.2471T > $\mathrm{C}$ (exon 2) in 593 birds of KNC (Fig 1; Table 2). In particular, the WHC, pH2, $\mathrm{L}^{*}$, and $\mathrm{b}^{*}$ traits of the thigh meat can directly affect tenderness.

Previous studies have been reported that increasing the $\mathrm{pH}$ in the meat tends to decrease the WHC; consequently, decreasing the WHC is likely to reduce the $\mathrm{L}^{*}$

(A) HSPB1 g.526A>G (5’UTR)

(B) CRYAB g.2471C >T (exon2)
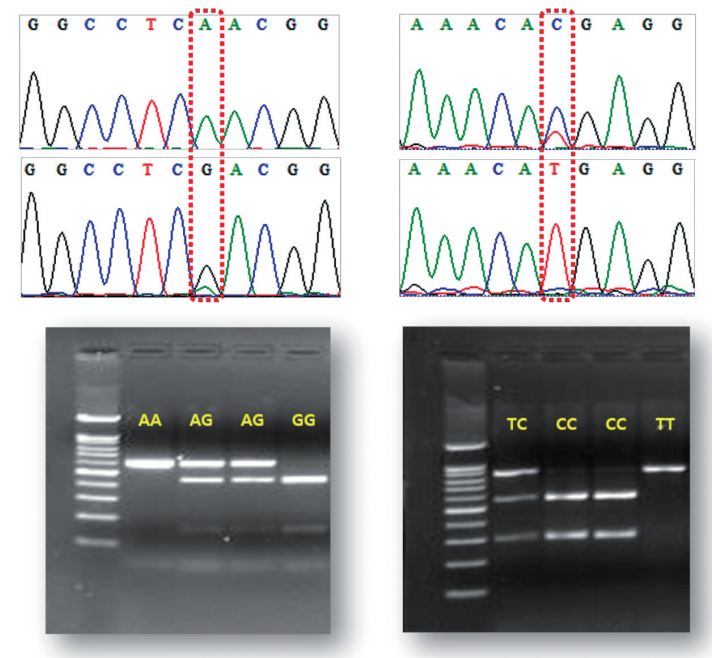

Fig. 1. The evidence of SNPs used to genotype the HSPB1 (A) and $C R Y A B$ genes (B).

Table 2. Associations of the SNPs in HSPB1 and CRYAB genes with meat quality traits in Korean native chickens

\begin{tabular}{|c|c|c|c|c|c|c|c|}
\hline Gene & Trait & P-value & $\mathrm{AA}$ & AG & GG & Additive & Dominant \\
\hline \multirow[t]{22}{*}{$H S P B 1$} & Br_WHC & 0.800 & $64.15 \pm 0.86$ & $63.52 \pm 0.61$ & $63.56 \pm 0.69$ & $-0.33 \pm 0.7$ & $0.29 \pm 0.57$ \\
\hline & Br_H2O & 0.717 & $4.29 \pm 1.1 \mathrm{E}-03$ & $4.29 \pm 8.0 \mathrm{E}-04$ & $4.29 \pm 0.01$ & $0 \pm 0$ & $0 \pm 0$ \\
\hline & Br_cProtein & 0.247 & $24.35 \pm 0.05$ & $24.44 \pm 0.03$ & $24.43 \pm 0.04$ & $0.05 \pm 0.04$ & $-0.04 \pm 0.03$ \\
\hline & Br_cFat & 0.062 & $0.8 \pm 0.01$ & $0.82 \pm 0.01$ & $0.84 \pm 0.01$ & $0 \pm 0.01$ & $-0.01 \pm 0$ \\
\hline & Br_cAsh & 0.153 & $1.16 \pm 0.01$ & $1.16 \pm 0.01$ & $1.19 \pm 0.01$ & $-0.01 \pm 0.01$ & $-0.01 \pm 0$ \\
\hline & Br_Collagen & 0.674 & $1.93 \pm 0.04$ & $1.96 \pm 0.03$ & $1.99 \pm 0.03$ & $0 \pm 0.03$ & $-0.02 \pm 0.03$ \\
\hline & Leg_WHC & 0.010 & $62.34 \pm 0.61$ & $60.93 \pm 0.41$ & $62.66 \pm 0.46$ & $-1.57 \pm 0.53$ & $-0.16 \pm 0.41$ \\
\hline & Leg_H2O & 0.225 & $74.99 \pm 0.12$ & $74.93 \pm 0.09$ & $75.15 \pm 0.11$ & $-0.13 \pm 0.1$ & $-0.08 \pm 0.08$ \\
\hline & Leg_cProtein & 0.443 & $22.01 \pm 0.13$ & $21.94 \pm 0.09$ & $21.79 \pm 0.11$ & $0.04 \pm 0.11$ & $0.1 \pm 0.09$ \\
\hline & Leg_cFat & 0.231 & $1.07 \pm 0.02$ & $1.11 \pm 0.01$ & $1.12 \pm 0.02$ & $0.01 \pm 0.02$ & $-0.02 \pm 0.01$ \\
\hline & Leg_cAsh & 0.117 & $1.11 \pm 0.01$ & $1.09 \pm 4.9 \mathrm{E}-03$ & $1.11 \pm 0.01$ & $-0.01 \pm 0$ & $0 \pm 0$ \\
\hline & Leg_Collagen & 0.875 & $2.03 \pm 0.03$ & $2.05 \pm 0.02$ & $2.05 \pm 0.03$ & $0.01 \pm 0.03$ & $0 \pm 0.02$ \\
\hline & Br_Cooking loss & 0.713 & $20.87 \pm 0.29$ & $20.59 \pm 0.19$ & $20.67 \pm 0.22$ & $-0.17 \pm 0.25$ & $0.09 \pm 0.2$ \\
\hline & Br_pH1 & 0.804 & $1.81 \pm 0.01$ & $1.81 \pm 0.01$ & $1.81 \pm 0.01$ & $0 \pm 0.01$ & $0 \pm 0.01$ \\
\hline & Br_pH2 & 0.114 & $1.74 \pm 0$ & $1.76 \pm 0.01$ & $1.76 \pm 0.01$ & $0 \pm 0$ & $-0.01 \pm 0$ \\
\hline & Br_Delta_pH & 0.365 & $0.38 \pm 0.04$ & $0.37 \pm 0.03$ & $0.32 \pm 0.03$ & $0.02 \pm 0.03$ & $0.02 \pm 0.02$ \\
\hline & $\mathrm{Br} \_\mathrm{L} *$ & 0.384 & $59.25 \pm 0.48$ & $59.92 \pm 0.33$ & $60.08 \pm 0.38$ & $0.24 \pm 0.4$ & $-0.41 \pm 0.32$ \\
\hline & Br_a* & 0.414 & $1.95 \pm 0.02$ & $1.99 \pm 0.02$ & $1.97 \pm 0.02$ & $0.02 \pm 0.02$ & $0 \pm 0.01$ \\
\hline & Br_b* & 0.986 & $21.28 \pm 0.19$ & $21.30 \pm 0.15$ & $21.32 \pm 0.16$ & $0 \pm 0.13$ & $-0.01 \pm 0.11$ \\
\hline & Leg_Cooking loss & 0.813 & $29.55 \pm 0.54$ & $29.93 \pm 0.38$ & $29.86 \pm 0.43$ & $0.23 \pm 0.44$ & $-0.15 \pm 0.36$ \\
\hline & Leg_pH1 & 0.967 & $6.45 \pm 0.04$ & $6.43 \pm 0.03$ & $6.44 \pm 0.03$ & $-0.01 \pm 0.04$ & $0 \pm 0.03$ \\
\hline & Leg_pH2 & 0.085 & $6.03 \pm 0.06$ & $6.13 \pm 0.04$ & $6.23 \pm 0.04$ & $0 \pm 0.05$ & $-0.09 \pm 0.04$ \\
\hline
\end{tabular}


Table 2. Continued

\begin{tabular}{|c|c|c|c|c|c|c|c|}
\hline Gene & Trait & P-value & $\mathrm{AA}$ & $\mathrm{AG}$ & GG & Additive & Dominant \\
\hline & Leg_Delta_pH & 0.935 & $0.26 \pm 0.02$ & $0.26 \pm 0.02$ & $0.25 \pm 0.02$ & $0 \pm 0.02$ & $0 \pm 0.02$ \\
\hline & Leg_L* & 0.004 & $48.53 \pm 0.41$ & $49.32 \pm 0.28$ & $47.96 \pm 0.32$ & $-1.07 \pm 0.35$ & $0.28 \pm 0.28$ \\
\hline & Leg_a* & 0.746 & $13.69 \pm 0.20$ & $13.72 \pm 0.14$ & $13.57 \pm 0.16$ & $0.09 \pm 0.16$ & $0.06 \pm 0.13$ \\
\hline & Leg_b* & 0.018 & $20.42 \pm 0.16$ & $20.53 \pm 0.11$ & $20.03 \pm 0.12$ & $-0.3 \pm 0.14$ & $0.19 \pm 0.11$ \\
\hline \multirow[t]{26}{*}{$C R Y A B$} & Br_WHC & 0.998 & $63.67 \pm 0.91$ & $63.72 \pm 0.64$ & $63.74 \pm 0.87$ & $0.01 \pm 0.79$ & $-0.03 \pm 0.69$ \\
\hline & Br_H2O & 0.371 & $4.29 \pm 1.0 \mathrm{E}-03$ & $4.29 \pm 0.01$ & $4.29 \pm 1.0 \mathrm{E}-03$ & 0 & 0 \\
\hline & Br_cProtein & 0.761 & $24.40 \pm 0.05$ & $24.42 \pm 0.03$ & $24.38 \pm 0.05$ & $0.03 \pm 0.04$ & $0 \pm 0.04$ \\
\hline & Br_cFat & 0.950 & $0.82 \pm 0.01$ & $0.82 \pm 0.01$ & $0.82 \pm 0.01$ & $0 \pm 0.01$ & $0 \pm 0.01$ \\
\hline & Br_cAsh & 0.059 & $1.15 \pm 0.01$ & $1.17 \pm 0.01$ & $1.20 \pm 0.01$ & $0 \pm 0.01$ & $-0.02 \pm 0$ \\
\hline & Br_Collagen & 0.725 & $1.98 \pm 0.04$ & $1.95 \pm 0.03$ & $1.99 \pm 0.04$ & $-0.03 \pm 0.04$ & $0 \pm 0.03$ \\
\hline & Leg_WHC & 0.354 & $60.92 \pm 0.64$ & $62.03 \pm 0.45$ & $62.21 \pm 0.62$ & $0.47 \pm 0.59$ & $-0.63 \pm 0.5$ \\
\hline & Leg_H2O & 0.126 & $75.12 \pm 0.13$ & $74.93 \pm 0.09$ & $75.18 \pm 0.13$ & $-0.22 \pm 0.11$ & $-0.02 \pm 0.09$ \\
\hline & Leg_cProtein & 0.117 & $21.95 \pm 0.14$ & $21.94 \pm 0.11$ & $21.61 \pm 0.14$ & $0.15 \pm 0.12$ & $0.16 \pm 0.11$ \\
\hline & Leg_cFat & 0.401 & $1.09 \pm 0.02$ & $1.11 \pm 0.01$ & $1.14 \pm 0.02$ & $-0.01 \pm 0.02$ & $-0.02 \pm 0.02$ \\
\hline & Leg_cAsh & 0.340 & $1.09 \pm 7.8 \mathrm{E}-03$ & $1.11 \pm 0.01$ & $1.11 \pm 0.01$ & $0 \pm 0$ & $0 \pm 0$ \\
\hline & Leg_Collagen & 0.749 & $2.05 \pm 0.03$ & $2.07 \pm 0.02$ & $2.04 \pm 0.03$ & $0.02 \pm 0.03$ & $0 \pm 0.02$ \\
\hline & Br_Cooking loss & 0.646 & $20.92 \pm 0.30$ & $20.67 \pm 0.21$ & $20.95 \pm 0.29$ & $-0.26 \pm 0.28$ & $-0.01 \pm 0.24$ \\
\hline & Br_pH1 & 0.249 & $1.79 \pm 0.01$ & $1.82 \pm 0.01$ & $1.81 \pm 0.01$ & $0.02 \pm 0.01$ & $0 \pm 0.01$ \\
\hline & Br_pH2 & 0.691 & $1.76 \pm 0.01$ & $1.76 \pm 0.01$ & $1.75 \pm 0.01$ & $0 \pm 0$ & $0 \pm 0$ \\
\hline & Br_Delta_pH & 0.203 & $0.29 \pm 0.04$ & $0.37 \pm 0.03$ & $0.39 \pm 0.04$ & $0.02 \pm 0.03$ & $-0.05 \pm 0.03$ \\
\hline & Br_L* & 0.150 & $60.65 \pm 0.53$ & $59.74 \pm 0.37$ & $59.05 \pm 0.51$ & $-0.11 \pm 0.47$ & $0.79 \pm 0.4$ \\
\hline & Br_a* & 0.395 & $1.97 \pm 0.03$ & $1.98 \pm 0.02$ & $1.94 \pm 0.03$ & $0.02 \pm 0.02$ & $0.01 \pm 0.02$ \\
\hline & $\mathrm{Br} \_\mathrm{b}^{*}$ & 0.429 & $21.31 \pm 0.20$ & $21.28 \pm 0.15$ & $21.05 \pm 0.19$ & $0.09 \pm 0.14$ & $0.12 \pm 0.12$ \\
\hline & Leg_Cooking loss & 0.292 & $29.37 \pm 0.61$ & $29.59 \pm 0.43$ & $30.54 \pm 0.58$ & $-0.36 \pm 0.51$ & $-0.58 \pm 0.45$ \\
\hline & Leg_pH1 & 0.740 & $6.47 \pm 0.04$ & $6.47 \pm 0.02$ & $6.44 \pm 0.03$ & $0.02 \pm 0.03$ & $0.01 \pm 0.03$ \\
\hline & Leg_pH2 & 0.137 & $6.23 \pm 0.06$ & $6.17 \pm 0.04$ & $6.04 \pm 0.06$ & $0.03 \pm 0.06$ & $0.09 \pm 0.05$ \\
\hline & Leg_Delta_pH & 0.505 & $0.25 \pm 0.02$ & $0.26 \pm 0.01$ & $0.30 \pm 0.02$ & $-0.01 \pm 0.02$ & $-0.02 \pm 0.02$ \\
\hline & Leg_L* & 0.780 & $48.56 \pm 0.36$ & $48.57 \pm 0.25$ & $48.27 \pm 0.35$ & $0.15 \pm 0.33$ & $0.14 \pm 0.28$ \\
\hline & Leg_a* & 0.190 & $13.42 \pm 0.21$ & $13.81 \pm 0.15$ & $13.58 \pm 0.20$ & $0.31 \pm 0.17$ & $-0.08 \pm 0.15$ \\
\hline & Leg_b* & 0.554 & $20.29 \pm 0.14$ & $20.32 \pm 0.10$ & $20.14 \pm 0.14$ & $0.1 \pm 0.13$ & $0.07 \pm 0.11$ \\
\hline
\end{tabular}

Br: breast muscle; Leg: thigh muscle; cFat: crude fat content (\%); cAsh: crude ash content (\%); H2O: crude moisture (\%); cProtein: crude Protein; L*: CIE lightness value; a*: CIE redness value; b*: CIE yellowness; WHC; water holding capacity (\%); pH1: after slaughter 15 min $\mathrm{pH} ; \mathrm{pH} 2$ : ultimate $\mathrm{pH}$

and b* values of the meat's color (Qiao et al., 2001). Appropriate moisture levels in meat can impart a soft texture and enrich the flavor of the gravy. In addition, the water content of the meat can affect its color, as too much water will cause it to look pale. In addition, the lower moisture content of the dark meat can make it less desirable to consumers. It has also been reported that $\mathrm{pH}$ changes the water holding capacity of the meat, and thus alters the color of the meat. In light of these results, the tenderness of meat from cattle is considered to be affected by HSPB1, and changes in $\mathrm{pH}$ were confirmed to be significantly associated with the expression of HSPB1. This study confirmed that high $\mathrm{pH}$ in animals of the GG genotype conferred a high WHC value. This may be attributed to the fact that KNC has darker meat than that of broilers, an observation supported by a previous study of KNC meat quality (Jung et al., 2011).

The chicken QTLdb (http://www.animalgenome.org/ cgi-bin/QTLdb/GG/index) includes QTLs for 10 different traits, including meat color and drip loss traits. The QTLs related to the color of thigh meat were found in GGA1, 2, 11, 26 (Jia et al., 2012; Yoshida et al., 2013). In these QTL results, the $\mathrm{b}^{*}$ value-affected QTLs were found in GGA1 and GGA2; meanwhile the other QTLs in GGA11 and GGA26 were not associated with thigh meat coloration. In addition, similar WHC traits, such as drip loss trait QTLs, were reported in GGA1, 11, and 14 (Nadaf et al., 2007; Jia et al., 2012). These QTL regions (not including GGA19) mostly affected breast meat coloration, because these studies did not measure traits separately. Therefore, more research into thigh meat color and WHC traits are needed, because HSPB1 is located on the 
Table 3. Associations of the SNPs in HSPB1 and CRYAB genes with the clinical-chemical traits in Korean native chickens

\begin{tabular}{|c|c|c|c|c|c|c|c|}
\hline Gene & Trait & P-value & $\mathrm{AA}$ & $\mathrm{AG}$ & GG & Additive & Dominant \\
\hline \multirow[t]{8}{*}{$H S P B 1$} & Glu & 0.448 & $254.57 \pm 2.73$ & $258.23 \pm 1.89$ & $256.22 \pm 2.14$ & $2.83 \pm 2.32$ & $-0.82 \pm 1.86$ \\
\hline & T_Pro & 0.995 & $4.21 \pm 0.07$ & $4.21 \pm 0.05$ & $4.2 \pm 0.05$ & $0 \pm 0.06$ & $0 \pm 0.05$ \\
\hline & GPT & 0.741 & $2.91 \pm 0.04$ & $2.94 \pm 0.03$ & $2.91 \pm 0.03$ & $0.02 \pm 0.03$ & $0 \pm 0.02$ \\
\hline & Cre & 0.589 & $-0.18 \pm 0.03$ & $-0.22 \pm 0.02$ & $-0.23 \pm 0.02$ & $-0.01 \pm 0.02$ & $0.02 \pm 0.02$ \\
\hline & HDL_c & 0.014 & $100.57 \pm 3.80$ & $101.51 \pm 3.02$ & $92.47 \pm 3.27$ & $-4.98 \pm 2.48$ & $4.05 \pm 2.12$ \\
\hline & T_Cho & 0.295 & $135.77 \pm 4.23$ & $138.41 \pm 3.15$ & $132.41 \pm 3.51$ & $4.32 \pm 3.14$ & $1.67 \pm 2.65$ \\
\hline & GOT & 0.736 & $5.36 \pm 0.04$ & $5.37 \pm 0.02$ & $5.4 \pm 0.03$ & $-0.01 \pm 0.03$ & $-0.01 \pm 0.02$ \\
\hline & Amy & 0.010 & $5.35 \pm 0.07$ & $5.38 \pm 0.05$ & $5.13 \pm 0.05$ & $-0.13 \pm 0.06$ & $0.1 \pm 0.05$ \\
\hline Gene & Trait & P-value & $\mathrm{CC}$ & $\mathrm{CT}$ & $\mathrm{TT}$ & Additive & Dominant \\
\hline \multirow[t]{8}{*}{$C R Y A B$} & Glu & 0.734 & $259.39 \pm 3.12$ & $256.43 \pm 2.23$ & $256.77 \pm 3.01$ & $-1.64 \pm 2.67$ & $1.3 \pm 2.35$ \\
\hline & T_Pro & 0.968 & $4.22 \pm 0.08$ & $4.24 \pm 0.05$ & $4.23 \pm 0.07$ & $0.01 \pm 0.06$ & $0 \pm 0.05$ \\
\hline & GPT & 0.830 & $2.93 \pm 0.05$ & $2.95 \pm 0.03$ & $2.92 \pm 0.05$ & $0.02 \pm 0.04$ & $0 \pm 0.03$ \\
\hline & Cre & 0.573 & $-0.22 \pm 0.03$ & $-0.18 \pm 0.02$ & $-0.2 \pm 0.03$ & $0.03 \pm 0.03$ & $-0.01 \pm 0.02$ \\
\hline & HDL_c & 0.900 & $98.87 \pm 4.11$ & $100.76 \pm 3.29$ & $100.73 \pm 3.95$ & $0.95 \pm 2.83$ & $-0.92 \pm 2.56$ \\
\hline & T_Cho & 0.515 & $135.91 \pm 4.44$ & $136.47 \pm 3.32$ & $141.38 \pm 4.26$ & $-2.17 \pm 3.5$ & $-2.73 \pm 3.13$ \\
\hline & GOT & 0.504 & $5.33 \pm 0.05$ & $5.38 \pm 0.03$ & $5.42 \pm 0.04$ & $0 \pm 0.04$ & $-0.04 \pm 0.03$ \\
\hline & Amy & 0.975 & $5.28 \pm 0.07$ & $5.31 \pm 0.05$ & $5.31 \pm 0.07$ & $0.01 \pm 0.06$ & $0 \pm 0.05$ \\
\hline
\end{tabular}

Glu: Glucose (mg/dl); T_Pro: Total protein (g/dl); Cre: Creatinine (mg/dl); HDL-C: High-density lipoprotein cholesterol (mg/dl); T-Cho: Total cholesterol (mg/dl); GOT: Glutamic oxaloacetic transaminase (IU/L); Amy: Amylase (IU/L)

GGA19, and most previous studies have focused on the breast muscles. This further research is necessary because the thigh and breast muscles can be constructed via different mechanisms.

Moreover, HSPB1 was not reported to be associated with meat coloration, and the WHC-related QTL and association results only indicated that abdominal fat weight and content were affected by genes in the GGA19 region. In our previous QTL results, we could not identify any QTLs for either meat color or WHC traits in the GGA19 region. QTLs related to thigh meat coloration, WHC, and $\mathrm{pH}$ traits were found to be located in GGA8 (thigh $\mathrm{L}^{*}$ ), GGA10 (thigh Cooking Loss), GGA8, 24 (thigh WHC), and GGA5, 7, 17 (thigh pH). It is possible that the QTL results were affected by the additive effect estimation model, but these association results have dominant effects. Therefore, HSPB1 requires further study, in order to validate these findings in other breeds or populations. This candidate gene is significantly associated with thigh meat color and WHC traits.

\section{Associations with clinical-chemical traits}

The traits for meat tenderness can be affected by environmental stress, a fact that has been established by previous research (King et al., 2006). Investigations of the relationships between meat quality and changes in environmental stress have employed the quantification of clinical-chemical traits to determine an animal's health status; these studies will be useful in the development of genetic markers for stress resistance in animals, and for the development of meat quality evaluation methods. Interestingly, in this study, we identified significant associations between the additive and dominance effects of high-density lipoprotein cholesterol (HDL-c) and amylase (Amy) traits, via the SNP in HSPB1 (Table 3). High levels of HDL-c in the blood serum are positive indicators of animal and human health. Moreover, a high amylase content is indicative of good health, specifically in relation to metabolism (Ueha et al., 1971). The birds of the GG genotype had lower HDL-c and Amy values than birds of the AA and AG genotypes. This may indicate that the AA and AG genotypes confer good digestibility and health statuses. Interestingly, the birds of the GG genotype have significantly darker meat and higher $\mathrm{pH}$ values than the birds of the AA and AG genotypes.

The clinical-chemical components are factors that affect the likelihood of change in the direct meat quality, and are considered important factors to evaluate using functional studies. However, of these traits the serum can be seen as a particular indicator of nutritional status, and in the case of these traits, factors that can make a difference to the smooth supply of nutrients to the muscles affect the smoothness of the metabolism. In addition, we cannot exclude the possibility that HSPB1 acts pleiotropically on meat quality and clinical-chemical traits at the same time, as a factor of stress resistance. This is because it acts during stress to restore damaged proteins. Thus, the expression of the gene may affect the generation and modification of the protein, and these changes must be considered in order to fully understand the mechanism, because they provide a variety factors that may drive changes in phenotypic characteristics. However, further research is required to understand the relationship between the characteristics.

Clinical-chemical components have been used as useful biomarkers that can measure the current health 
status of animals (diseased or immune). However, chicken serum clinical-chemical traits cannot be used as indicator for health status because it was not established standard yet. However, if change in the various characteristics of the serum can affect the quality of meat and the health of the chickens relative to manage the health of the production side, it is considered to make use for animal breeding as genetic marker. In addition, clinicalchemical traits are a matter of developing breeds with a robustness that can adapt to global warming and the harsh environment of rapid climate change; these concerns are believed to be very important to preparations for future challenges in the livestock industry.

In this study, tests for the association between meat quality and animal clinical-chemical traits were performed using an SNP in HSPB1. The results indicate that birds of the GG genotype have dark meat, a tendency to have high $\mathrm{pH}$ values, and less HDL-c with Amy than animals of the AA or AG genotypes. With further verifications, these results can provide useful information with which to improve chicken meat quality and our understanding of the relationship between blood metabolism and meat quality.

\section{ACKNOWLEDGEMENTS}

This work was supported by a grant from the NextGeneration BioGreen 21 Program (No.PJ00813301), of the Rural Development Administration, Republic of Korea and the Golden Seed Project (No. PJ009925032015), Korea Institute of Planning \& Evaluation for Technology in Food, Agriculture Forestry \& Fisheries (IPET), republic of Korea.

\section{REFERENCES}

Bernard, C., I. Cassar-Malek, M. Le Cunff, H. Dubroeucq, G. Renand and J. F. Hocquette 2007 New indicators of beef sensory quality revealed by expression of specific genes. J. Agric. Food Chem., 55: 5229-5237

Calkins, C., T. Dutson, G. Smith, Z. Carpenter and G. Davis 1981 Relationship of fiber type composition to marbling and tenderness of bovine muscle. J. Food Sci., 46: 708-710

D’Alessandro, A., S. Rinalducci, C. Marrocco, V. Zolla, F. Napolitano and L. Zolla 2012 Love me tender: an Omics window on the bovine meat tenderness network. J. Proteomics, 75: 43604380

Destefanis, G., A. Brugiapaglia, M. Barge and E. Dal Molin 2008 Relationship between beef consumer tenderness perception and Warner-Bratzler shear force. Meat Sci., 78: 153-156

Gilmour, A. R., B. Gogel, B. Cullis, R. Thompson and D. Butler
2009 ASReml user guide release 3.0. VSN International Ltd, Hemel Hempstead, UK

Guillemin, N., M. Bonnet, C. Jurie and B. Picard 2011 Functional analysis of beef tenderness. J. Proteomics, 75: 352-365

Herrera-Mendez, C. H., S. Becila, A. Boudjellal and A. Ouali 2006 Meat ageing: Reconsideration of the current concept. Trends Food Sci. Technol., 17: 394-405

Jia, X., S. Chen, H. Zhou, D. Li, W. Liu and N. Yang 2012 Copy number variations identified in the chicken using a 60K SNP BeadChip. Anim. Genet., 44: 276-284

Jung, Y. K., H. J. Jeon, S. Jung, J. H. Choe, J. H. Lee, K. N. Heo, B. S. Kang and C. Jo 2011 Articles : Comparison of quality traits of thigh meat from Korean native chickens and broilers. Korean J. Food Sci. Anim. Resour., 31: 684-692

Jung, S., H. J. Kim, H. J. Lee, D. W. Seo, J. H. Lee, H. B. Park, C. Jo and K. C. Nam 2015 Comparison of pH, Water Holding Capacity and Color among Meats from Korean Native Chickens. Korean J. Poult. Sci., 422: 101-108

Kim, J. H., S. H. Cho, P. N. Seong, D. W. Jeong, T. S. In, K. H. Hah, M. O. Jung, B. Y. Park, J. M. Lee and D. H. Kim 2009 Relationship between sensory property and Warner-Bratzler shear force for prediction of tenderness for branded Hanwoo beef. Korean J. Food Sci. Anim. Resour., 29: 40-46

King, D., C. S. Pfeiffer, R. Randel, T. Welsh, R. Oliphint, B. Baird, K. Curley, R. Vann, D. Hale and J. Savell 2006 Influence of animal temperament and stress responsiveness on the carcass quality and beef tenderness of feedlot cattle. Meat Sci., $\mathbf{7 4}$ 546-556

Lim, D., S. H. Lee, Y. M. Cho, B. H. Choi, H. H. Choi, H. H. Seong, S. K. Hong and N. K. Kim 2012 Association of heat shock protein beta 1 (HSPB1) gene expression with tenderness in loin muscle of Korean cattle (Hanwoo). J. Life Sci., 22: 1523-1528

Miller, S. A., D. D. Dykes and H. F. Polesky 1988 A simple salting out procedure for extracting DNA from human nucleated cells. Nucleic Acids Res., 16: 1215

Nadaf, J., H. Gilbert, F. Pitel, C. M. Berri, K. Feve, C. Beaumont, M. J. Duclos, A. Vignal, T. E. Porter and J. Simon 2007 Identification of QTL controlling meat quality traits in an F2 cross between two chicken lines selected for either low or high growth rate. BMC Genomics, 8: 155

Qiao, M., D. Fletcher, D. Smith and J. Northcutt 2001 The effect of broiler breast meat color on $\mathrm{pH}$, moisture, water-holding capacity, and emulsification capacity. Poult. Sci., 80: 676-680

Sun, Y., G. Zhao, R. Liu, M. Zheng, Y. Hu, D. Wu, L. Zhang, P. Li and J. Wen 2013 The identification of 14 new genes for meat quality traits in chicken using a genome-wide association study. BMC Genomics, 14: 458

Ueha, T., O. Catanzaro, R. Hanson and R. H. Lindsay 1971 Metabolic alterations accompanying alpha-amylase secretion by rat parotid tissue in vitro. Am. J. Physiol., 220: 312-318

Yoshida, M., A. Ishikawa, T. Goto, N. Goto, M. Nishibori and M. Tsudzuki 2013 QTL mapping for meat color traits using the F2 intercross between the Oh-Shamo (Japanese Large Game) and White Leghorn Chickens. J. Poult. Sci., 50: 198-205

Zhang, Z., Y. Liu, X. Jiang, H. Du and Q. Zhu 2008 Study on association of single nucleotide polymorphism of CAPN1 gene with muscle fibre and carcass traits in quality chicken populations. J. Anim. Breed. Genet., 125: 258-264 